\title{
VEHICULAR TUNNELS UNDER THE HUDSON RIVER.*
}

BY

\author{
MARTIN SCHREIBER, M.Am.Soc.C.E., \\ Chief Engineer, Public Service Railway Co., Newark, New Jersey.
}

THE population of metropolitan New York, say within a radius of ten miles, is about $7,000,000$ people. On Long Island, and in Brooklyn and Queens, which are separated from Manhattan by the East River, and in Richmond, there are 2,500,000 people. On the Island of Manhattan and the Bronx and to the north within this radius, the population is $3,000,000$ people. On the New Jersey side of the Hudson River there are about I,500,000 people.

The transportation needs for such a community present a tremendous problem. The problem is complicated by the fact that metropolitan New York is not only the great gateway of the country, but one of the great ports of the world. Here we have railroads, aggregating approximately 29,000 miles, terminating on the Jersey side of the Hudson. On the Manhattan side of the Hudson there are termini representing about $I I, 000$ miles, making a complete termini in the metropolitan area of approximately 40,000 miles of railroad. Moreover, there are seventy-seven foreign steamship lines operating from the port to all parts of the globe. There are more manufacturers in this district than the combined number in Chicago, Philadelphia and St. Louis. In this metropolitan area, Long Island and Manhattan districts are tied together over the East River by a number of bridges. These are the Brooklyn, Manhattan, Williamsburg and Queensboro bridges, which are among the largest structures of their kind in the world. Crossing the East River on these bridges are tweny-six railroad tracks and four highway roads for vehicles, with fourteen additional tracks in tunnels.

In striking contrast to the facilities over the East River are those across the Hudson River connecting the New Jersey district with the remainder of the metropolitan area. Here there are only six railroad tracks operating through tunnels under the Hudson River, two by the Pennsylvania Railroad and four by the Hudson

* Presented at the Stated Meeting held Wednesday, December I8, i9r8. VoL. 187, No. III9-22 
and Manhattan Railroad. There are no highways at all. So the remaining business, either vehicular or passenger, must be transported by means of ferryboats.

Even to the most casual observer it must be evident that the New Jersey side of the metropolitan district is at a great disadvantage when compared to the remainder of the area. Taking the steam railroads, for example, with seventy-three per cent. of all the mileage entering the Port of New York, or termini representing about 29,000 miles, stopping on the Jersey side of the Hudson with the major part of their business to be done on the opposite side of the river, certainly creates a condition which is not economically sound.

In the early days it was not such a serious problem to ferry the cars, vehicles and people across the river. But as the district developed, more ferries, more tugs, more car floats and more lighters had to be brought into play, and now with the increased maritime business the river is congested with watercraft. Present facilities are entirely inadequate to meet the growing demands of the community, even under favorable conditions. When the river is blanketed with fog or filled with ice, not an uncommon occurrence, the whole transportation scheme is thrown out of gear. The stranger has this strongly impressed upon him if he happens to drive over the Lincoln Highway to Jersey City, for before he can get on a Cortlandt Street or Desbrosses Street ferryboat, we will say, it will be necessary for him to run a blockade of trucks, automobiles and other vehicles that clog Montgomery Street, Jersey City, for several blocks.

A large portion of the food supply for $7,000,000$ persons is brought to the piers on the west side of the Hudson by the railroads. Owing to the congested and generally inadequate terminal facilities there is wastage of perishable food products before distribution can be made.

The bridging of the Hudson River at New York is a question that has been before the people of the States of New York and New Jersey for at least thirty years. No doubt a bricige would have been constructed long ago if it had been possible to finance the proposition. Unfortunately, the first outlay for such a structure would be very great, as it would be necessary to build a bridge large enough to anticipate future as well as present needs. It would be very uneconomical to build two or more bridges, 
when a little more money spent for a given bridge would double its carrying capacity. This is especially true of such a bridge as has been proposed for the Hudson River, with a span of almost 3000 feet, which must be of abnormal width and strength to even carry its own weight. An idea of the magnitude of a Hudson River bridge may be obtained when it is realized that the bridge

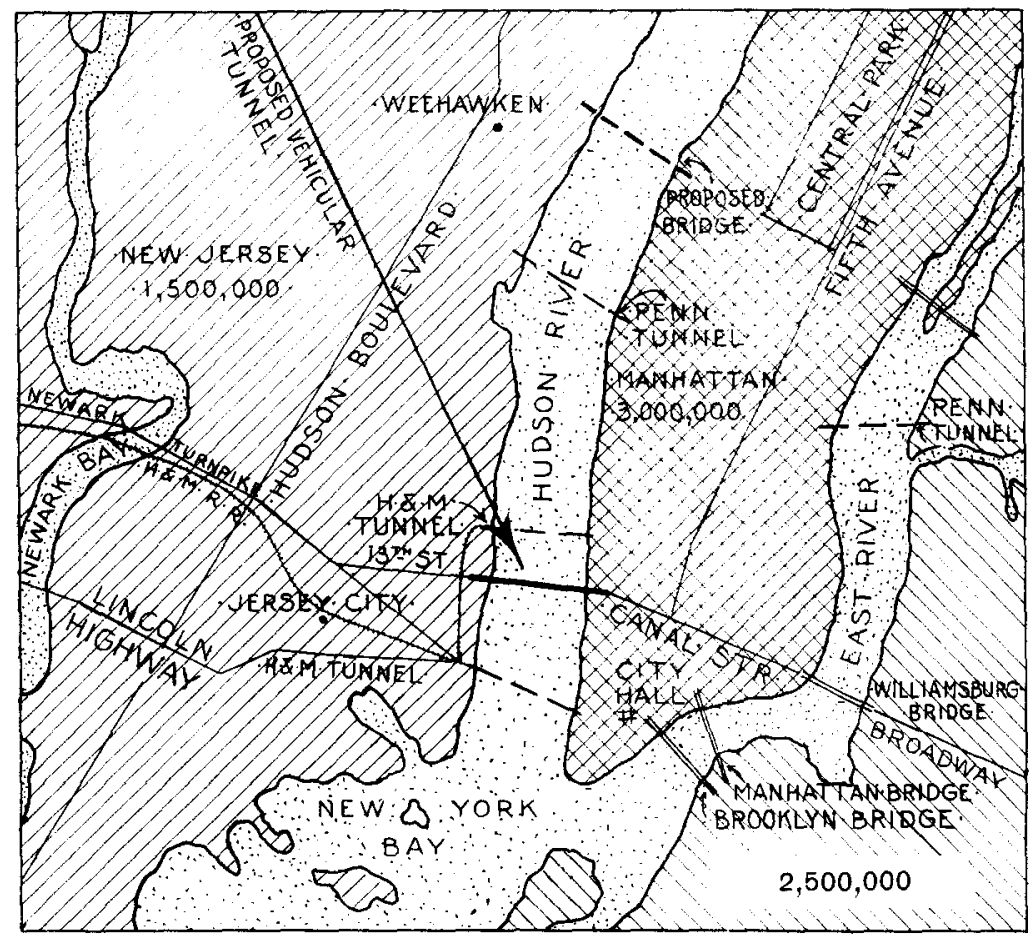

Map showing location of proposed vehicular tunnel.

proposed by Boller, Hodge \& Baird, consulting engineers for the New York State Bridge and Tunnel Commission, to be built at Fifty-seventh Street, would have had a single span of almost twice the length of the Manhattan or Brooklyn Bridge spans. The plans called for a span longer than that of any bridge in the world. The proposed bridge was to be I 70 feet clear above high water and its towers to support the suspension cables were to reach 600 feet above the water. The width of the bridge was fixed at 204 feet. Its proposed capacity was eight tracks for rapid transit 
trains, two driveways (each thirty-six feet in width) and two eight-foot sidewalks. In I9I 3 the cost of the Fifty-seventh Street Bridge was estimated at $\$ 42,000,000$. No doubt it would now cost nearly double that amount and it would take from six to ten years to construct it.

Any one who has given thought to the traffic situation in the metropolitan area would say that such a bridge across the Hudson would be a tremendous boon to both New York and New Jersey, and would go a long way toward providing and equalizing transportation facilities. On the other hand, as pointed out, the financing of such a project has its drawbacks. Naturally enough, with the development and possibilities of freight and passenger automobiles, many have turned their thoughts toward other means of crossing the Hudson, and tunnels naturally suggested themselves. In the first place, a tunnel could be built for a relatively nominal sum, say ten to fifteen million dollars, and the time of construction would not be more than two years. Again, it would not be a case of "putting all your eggs in the same basket," as a tunnel could be built in a comparatively short time, and, if it was successful, others could follow at any desired location. Further, it would seem that if we are not able to get a great bridge, with all the splendid benefits that would accrue, we should not deny ourselves any measure of improvement that may be within our reach.

In the last few years three separate reports have been made on the feasibility of vehicular tunnels under the Hudson River at New York:

(I) Report of Messrs. Jacobs \& Davies, Consulting Engineers for the New Jersey Interstate Bridge and Tunnel Commission.

(2) Report of Special Committee on Vehicular Tunnel Project, to Public Service Corporation of New Jersey.

(3) Report of General G. W. Goethals for the Interstate Bridge and Tunnel Commissions of New York and of New Jersey.

All three reports agreed on the one location, which was first proposed by Messrs. Jacobs \& Davies, and extends from Twelfth Street, Jersey City, to Canal Street, New York. The termini of the tunnel at both ends are located in the centre of the trucking and freight districts. The terminus on the Jersey side is not only in the midst of a busy industrial centre, but is also adjacent to 
the great freight yards of the Erie, Pennsylvania and Lackawanna Railroads and close to the Christopher, Barclay, Desbrosses, Chambers and Cortlandt Street Ferries. The tunnel would be in direct line with the Newark and Jersey City Turnpike, the Belleville Turnpike and Lincoln Highway on the Jersey side of the Hudson; while on the New York side, it would be in direct communication with the Manhattan and Williamsburg bridges to Brooklyn and Long Island. So, it is seen that this location is particularly favorable with relation to main traffic arteries. Also, not far from the vicinity of the terminus on the Jersey side is one of the largest trans-Atlantic terminals in existence. On the New York side are the piers of numerous steamship companies, such as the New England Navigation Company operating to Fall River and Portland; the Central Hudson Steamboat Company

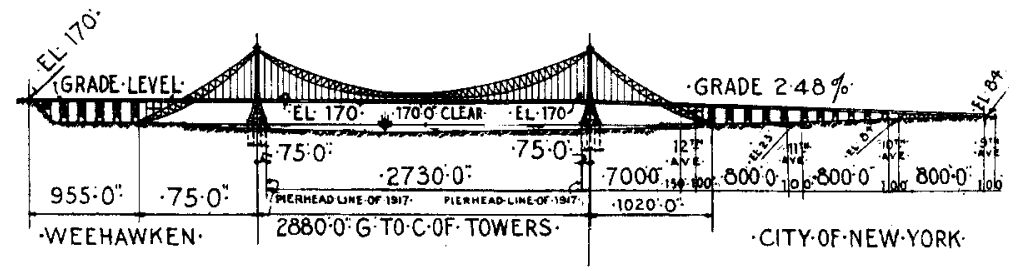

Proposed Hudson River bridge, near 57 th Street. $2880^{\circ} 0^{\prime \prime}$, center span; $4920^{\circ} 0^{\prime \prime}$, between anchorages; $8330^{\prime} \mathrm{o}^{\prime \prime}$. entire length from 9 th Avenue to top of Palisades; maximum grade, 2.48 per cent. (Boller, Hodge and Baird.)

with its Hudson River boats; the Royal Mail Steam Packet Line to Bermuda and the West Indies, and the Southern Steamship Company to the Gulf Ports.

It was estimated by Mr. Percy Ingalls, of the Special Committee of Public Service Corporation of New Jersey, referred to heretofore, that by 1920 at least $4,000,000$ vehicles a year will be crossing the five adjacent ferries and that at least 2,000,000 would use a tunnel if one were constructed. In this connection it is interesting to note that the Blackwall and Rotherhithe Tunnels under the Thames River, England, handle only about I,0oo,ooo vehicles each per annum.

When the unusually favorable location of the tunnel proposed is considered, it does not appear that there would be much of a risk involved in building at least a single tunnel between Twelfth Street, Jersey City, and Canal Street, New York. In addition to lending itself to vehicular business, such a tunnel could be 
adapted to almost any scheme for the development of the transportation systems of the Port of New York.

So far as the methods of construction of the proposed vehicular tunnel are concerned, there are differences of opinion as to certain engineering features. The first and third reports, already referred to, recommend that the tunnel be driven by the wellknown shield and compressed air method. This was the method used in constructing the present tunnels under the Hudson and East Rivers, and was also used for the existing tunnels under the Thames River, England. With this plan a shield chamber is sunk at one or both ends of the tunnel and the shield installed.

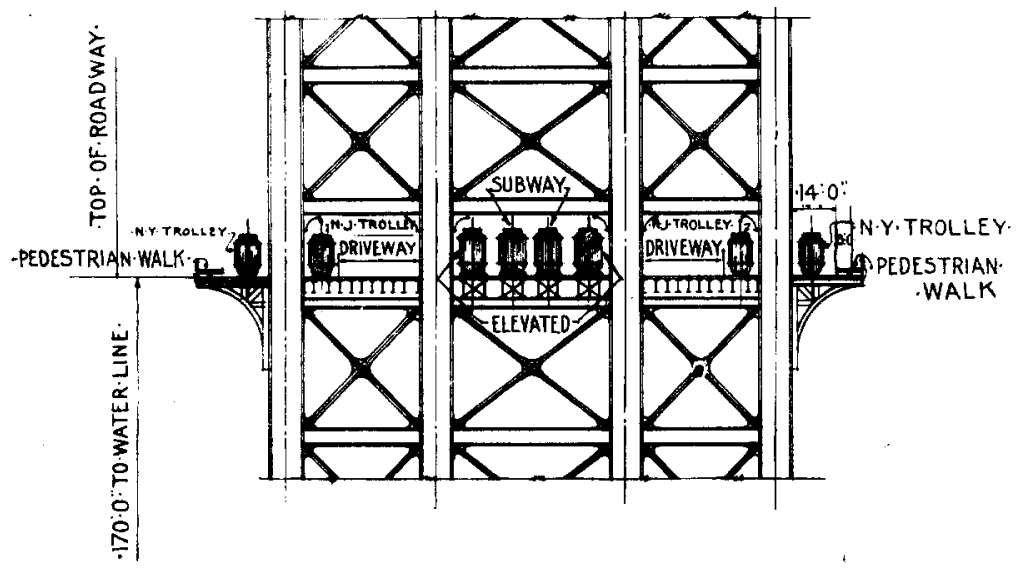

Sectional view of tower for proposed Hudson River bridge, near 57 th Street. (Boller, Hodge and Baird.)

For example, the shield in the case of the Pennsylvania Railroad tunnels across the Hudson at Thirty-fourth Street, as designed by $\mathrm{Mr}$. Charles M. Jacobs, the consulting engineer, was about eighteen feet long and twenty-three feet in diameter, and made of three-quarter-inch plates which also formed the cutting edge. The shield was forced forward by twenty-four hydraulic jacks that exerted a pressure of 3400 tons. As the shield was moved ahead by displacement of the silt or mucking through doors in the bulkhead, it was followed up by the installation of a cast-iron sectional lining that was bolted together and caulked watertight.

The first reports, recommending the usual shield-driven tunnel, included the customary iron lining. The third report, also recommending a shield-driven tunnel, included a special concrete 
block lining. The shield-driven tunnel has the advantage of being not only well tried but may be carried out without disturbing the surface of the land or water along the route of the tunnel, except, say, at the approaches. Although the first and third reports recommended the shield-driven tunnel, they do not recommend the same cross-section. Jacobs \& Davies' report proposes two single tubes approximately twenty-seven feet in diameter with seventeen foot roadways and a walk on each side. This arrangement would allow two lines of vehicles, one slow moving and one fast moving, in

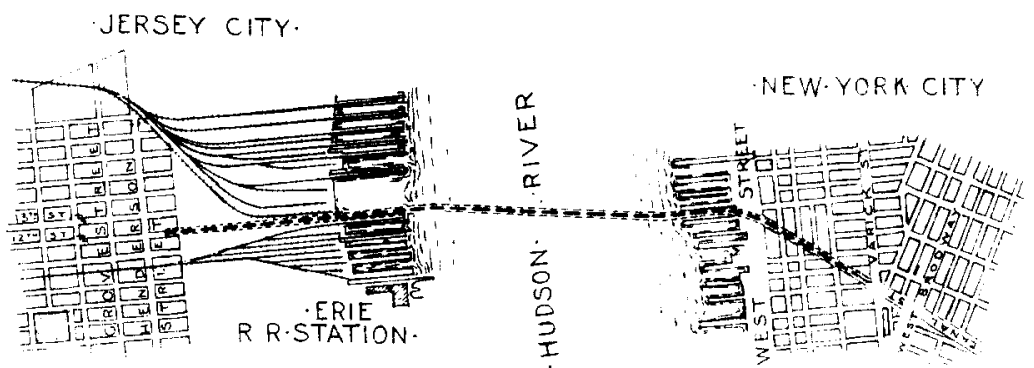

PLAN.

Proposed vehicular tunnel between I 2 th Street, Jersey City, and Canal Street, New York City. Total length. $9409^{\prime} 0^{\prime \prime} ;$ length between bulkhead lines $5495^{\prime} ;$ length between pierhead lines $3724^{\prime}$; maximum grade New Jersey approach 4.55 per cent.; maximum grade New York approach 3.85 per cent. (Burr, Modjeski and Moran.)

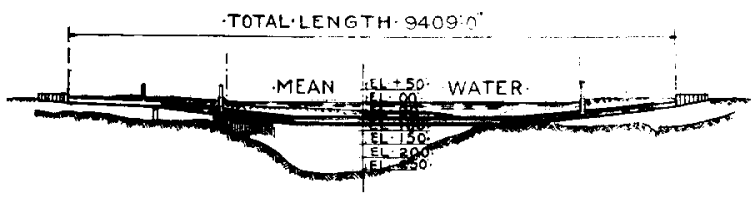

Profile. Maximum depth at low water $55^{\prime} 0^{\prime \prime}$.

each tube; or four lines of vehicles in both tunnels. It also has an advantage in natural ventilation, as vehicles moving in the same direction have a tendency to exhaust the foul air that is replaced with a certain quantity of fresh air from the mouth of the tunnel.

Gen. Geo. W. Goethals advocates a shield-driven single tube, thirty-six feet in diameter, with two eighteen-foot roadways, one superimposed above the other and a concrete floor between them. Such a cross-section would also allow four lines of vehicles, two of the faster-moving type (such as pleasure automobiles) on the upper floor, and two of the slower-moving vehicles (such as automobile trucks) on the lower floor. 
The second report, as proposed by Messrs. Wm. H. Burr, Ralph Modjeski and Daniel E. Moran, the board of engineers for Public Service Corporation of New Jersey, differed from the other two both in character of the cross-section of tunnel and in method of construction. This report proposes a single tube, having a seventeen-foot roadway, with an elliptical cross-section. The tunnel was to be of reinforced concrete and have a minimum thickness of four feet. It was to be an arch section and so designed as to sustain to the best advantage the varying pressures of water at different depths, so that the section really constituted what is known as an hydrostatic arch. The tube was intended to accommodate only two lines of vehicles running in

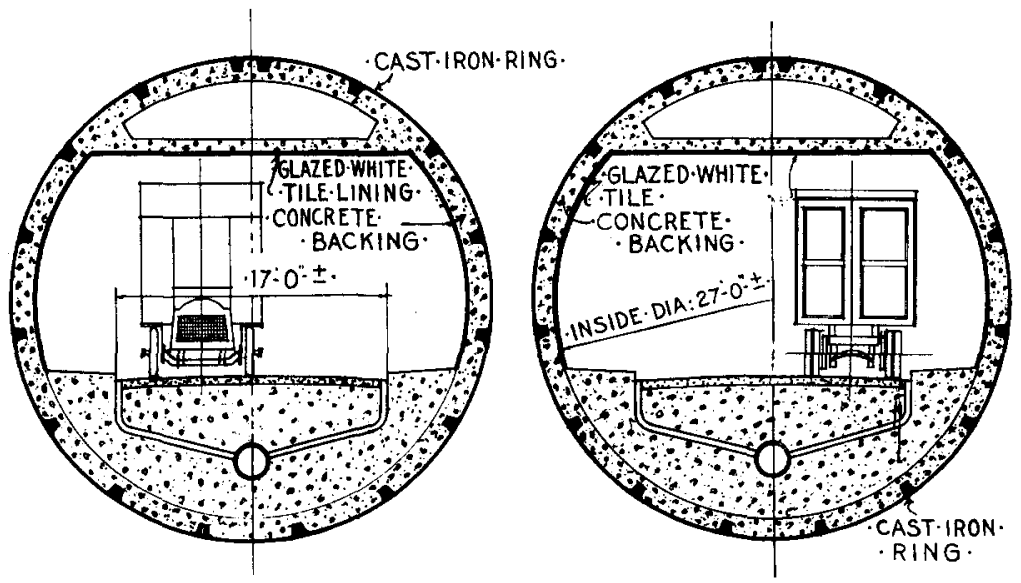

Cross section of proposed vehicular tunnels under Hudson River. (Jacobs and Davies.)

opposite directions. Its operation was to be similar to the Blackwall and Rotherhithe Tunnels under the Thames River. The maximum capacity of this tunnel was figured at 6,000,000 vehicles per year, two or three times as many as it was thought it would be called upon to accommodate for a long time. The entire length, from portal to portal, was 9409 feet, with 5495 feet between bulkhead lines. It was proposed to build the river section 2680 feet long, by excavating a trench so that the bottom of the same would be eighty feet below mean low water. The width of the trench at the bottom was to be forty feet and it was to be sloped off at an angle to the horizon of one to three. Piles were then to be driven in the trench on five-foot and eight-foot centres, and cut off at about seventy-eight feet below low water. 
These piles were to form a foundation for the reinforced concrete tunnel. Each section of the tunnel, which was to be eighty feet long, was to be completed on launchways at convenient locations. After closing these sections with timber bulkheads and towing them to the tunnel site they are to be sunk in place. After the sections were joined together by specially designed joints the bulkheads were to be removed. This method of construction is

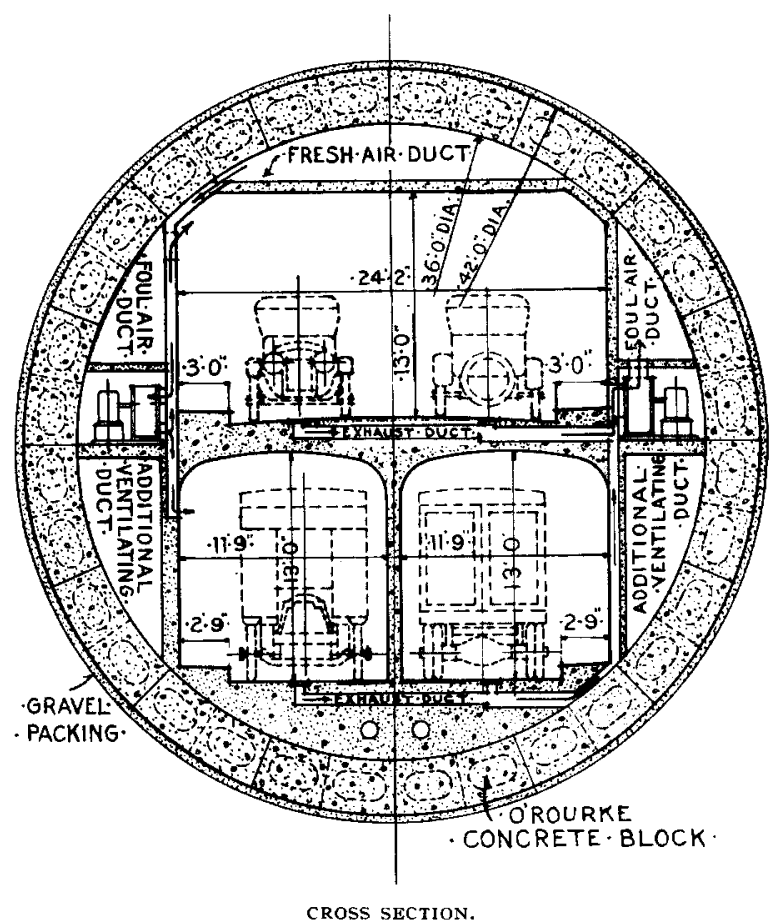

Proposed highway tunnel between Canal Street, New York, and 12 th Street, J ersey City. (Goelhals.)

not altogether new, as somewhat similar methods were used in connection with the Detroit River Tunnel and the tunnel across the Harlem River, New York.

The remaining portions of the tunnel, between the portals and the river sections on each side of the river, were to be constructed by the open or the pneumatic caisson method. The advantage claimed for the trench method of construction was economy and least depth below mean low water, which was figured for the first time by the Government at fifty feet. 
In connection with the report of Public Service Corporation, the board of engineers made a special investigation of tunnel ventilation. Some engineers had doubted the practicability of operating a tunnel of the length proposed for motor vehicles on account of the danger of carbon-monoxide in the exhaust gases. although it had already been pointed out by Messrs. Jacobs \& Davies in their report that mechanical ventilation was feasible.

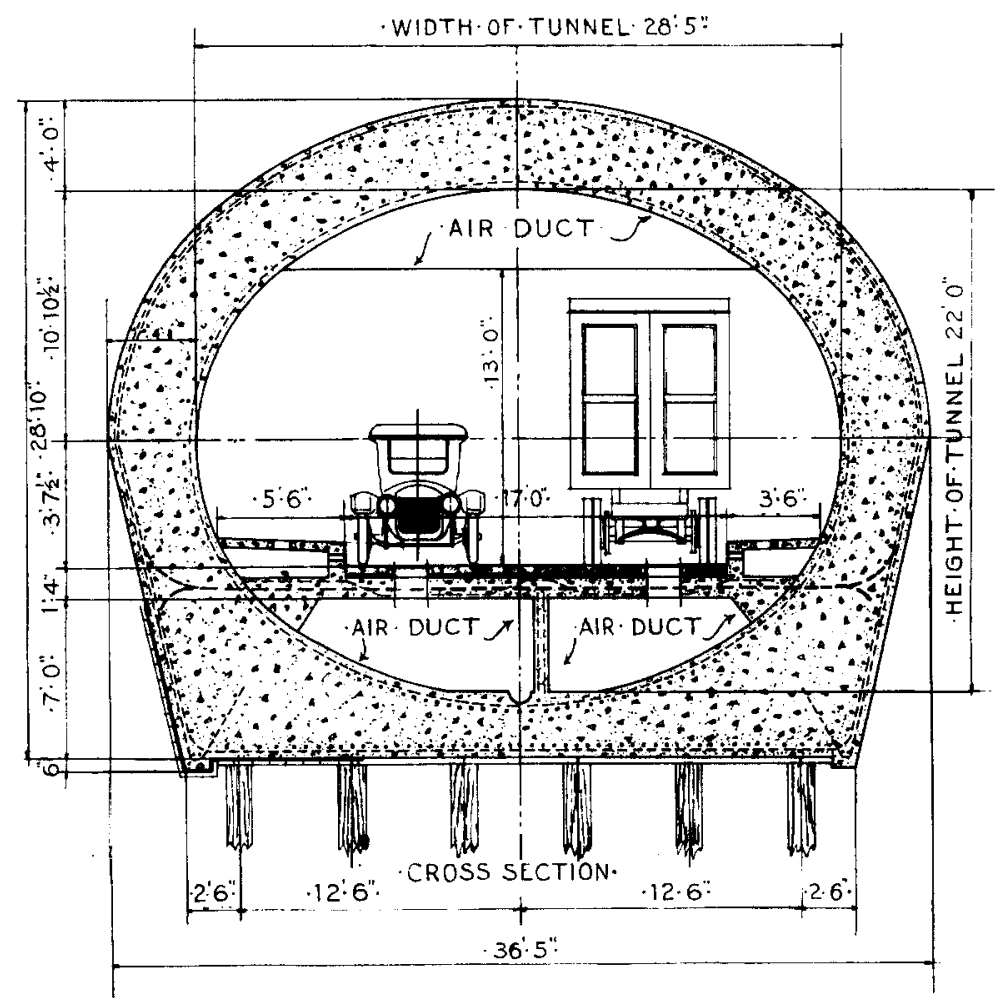

Proposed highway tunnel between Canal Street, New York, and I 2 th Street, Jersey City. (Burr, Modjeski and Moran.)

Assuming that all other engineering problems, such as construction and drainage, could be overcome if it were impossible to remove or dilute the poisonous gases, it was evident that the entire project would have to be abandoned. $U_{p}$ to the time the preliminary study of the tunnel was undertaken very little information was available concerning waste from gas engines, although all other information (such as proper proportion of air to gas 
for perfect combustion) was readily obtainable. Fatalities, due to exhaust gases in garages, are becoming quite common, and this may cause more interest in the general subject of exhaust gases in the near future.

In considering the ventilation of the tunnel, the number of cars that might be in the flume at any one time could be assumed; likewise the average horsepower per motor, the speed at which the car would run and the average mileage per gallon of gasoline. So it was quite an easy matter to calculate the quantity of fresh air necessary to take care of the operation of the motors. At the same time it was necessary to ascertain how much air should be exhausted and how much air supplied per minute to make the air livable and to overcome the poisonous carbon-monoxide.

Various authorities have advanced different ideas as to the proper quantity of air to be supplied and exhausted, and some have gone so far as to say that it is impossible to ventilate a tunnel of this kind at all.

Four different schemes were given consideration for the ventilation of the tunnel:

First: Utilizing the suction of cars running through the tunnel. This idea was abandoned when the neutralizing effect of cars running in opposite directions was considered.

Second: Forcing large quantities of air in one end of the tunnel and exhausting at the other. This was eliminated when it was considered that the total exhaust gases in the tunnel would be forced to one end and would probably make the air at that point quite dangerous.

Third: Installing an exhaust system drawing all air from the tunnel and allowing fresh air to come in at the portals and through fresh air shafts which would be built at the bulkhead line on both shores of the river. This scheme was also considered impracticable when it was found that the condition would be similar to Scheme No. 2, except that considerable of the foul gases would be drawn to the centre of the tunnel, with very little fresh air to dilute them.

Fourth: To install a system of both supply and exhaust fans and ducts, with inlet and outlet openings at various points, so that the tunnel could be theoretically blocked off into sections, each section having its separate inlet and outlet opening. This plan was finally adopted.

With Scheme No. 4 arose the same old question as to the proper quantity of air necessary for both supply and exhaust. As before 
mentioned, little was known about the properties of exhaust gases, and, therefore, no stated quantities could be decided upon. For this reason the engineers decided to erect a test building of the same cross-sectional design and dimensions as the proposed tunnel and of sufficient length to enable a number of cars to enter, and then to install a ventilating system of such nature that the same
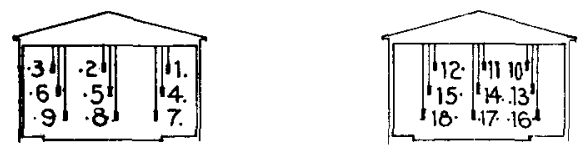

Section showing location of pipettes from front (east) end of building.
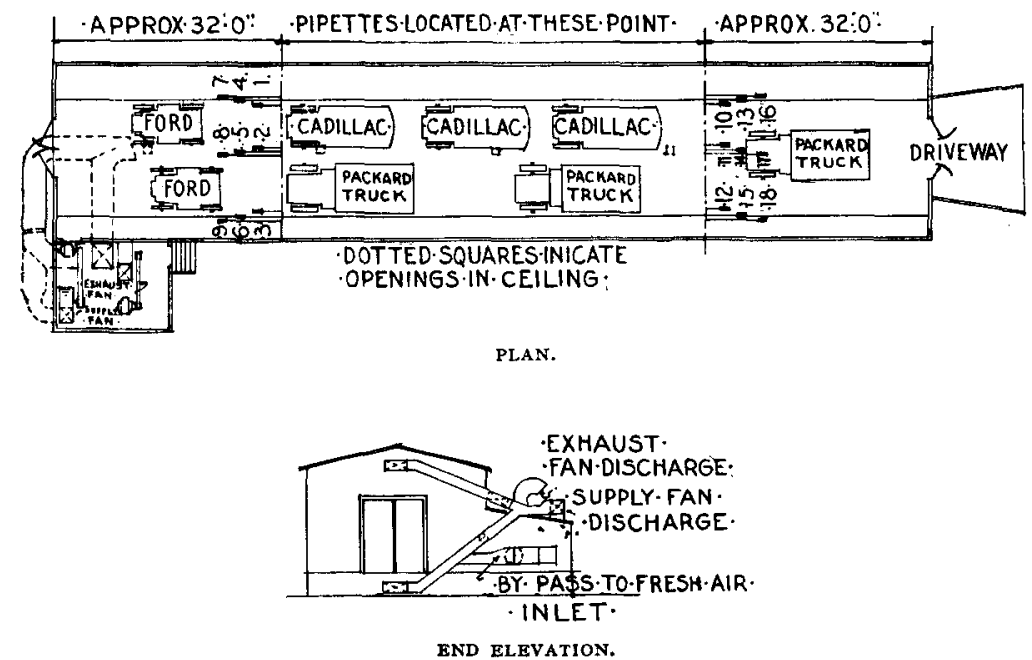

Sketch showing location of pipettes for gas analyses and various automobiles and trucks during tests at Experimental Building. Passaic wharf, Newark, N.J.

could be increased or decreased in capacity as occasions might demand.

Accordingly, a building I 25 feet in length, twenty-five feet in width and fifteen feet in height was constructed on the Passaic Wharf property of Public Service Railway Company at Newark. The cross-section of the building was an exact duplicate of the interior of the proposed tunnel. The interior of the building was lined with beaver board so that a smooth and uniform surface was obtained. When the doors were closed the building 
was practically airtight. Over the ceiling and under the floor spaces were left for ventilating ducts, which were installed and supplied with a number of openings controlled by dampers. The openings in the ceiling were twenty-five feet on centres, while the openings at the floor, which were in both the curb and walkway, were twelve and one-half feet on centres, placed diagonally opposite each other. The ducts were cross-connected at the rear of the building, so that the system could be interchangeable if required. The ducts were then brought down to exhaust and supply fans, which were installed in a small shed at one end and at the side of the building. These fans were built by the Buffalo Forge Company of approximately I 5,000 cubic feet of air per minute capacity, and were belted to direct current variable speed motors, which in turn were controlled by regulators, so that the speed and capacity of the fans could be varied as desired. In this fan room were also installed two Ellison draught gauges, one for each fan, so that constant readings as to the volume of air handled and frictional resistance could be carefully tabulated.

In the building, or improvised tunnel section, were operated eight automobiles, comprising two Ford Roadsters, three Cadillac Touring cars and three Packard trucks, which would give about the same conditions as would be found in a section of the tunnel if it were actually constructed.

There were various tests made, as follows:

I. Cars running normally, with no ventilation.

2. Cars racing, with no ventilation.

3. Cars running normally, with air being blown in at ceiling and exhausted at floor.

4. Cars racing, with air being blown in at ceiling and taken out at floor.

5. Cars running normally, with air being blown in at the floor or road line and exhausted at ceiling.

6. Cars racing, with air being blown in at floor line and exhausted at ceiling.

Chemical analyses of contaminated air were undertaken by Prof. Gellert Alleman, of Swarthmore, Penna. He was aided by Dr. H. Jermain Creighton, Assistant Professor of Chemistry, Swarthmore College, and Messrs. R. L. Hill and L. T. Sherwood.

It was considered necessary to make accurate determinations of the contaminated air near the floor, ceiling and the sections 
intervening between the floor and the ceiling. The contaminated air was collected in cylindrical pipettes over mercury. These pipettes were twenty-two centimetres long and four centimetres in diameter, and had a volume of approximately 250 cubic centimetres. Each pipette held about eight pounds of mercury. The pipettes were closed at each end by a glass stopcock. In order to prevent the pipettes from breaking under the weight of mercury when suspended for collecting samples, each pipette was suspended with a heavy canvas jacket to the top of which a loop of wire was attached. Eighteen pipettes were used in the experimental tunnel at one time. Nine of these were suspended onequarter the distance from either end. Each set of nine was arranged as follows: three midway between the top of the tunnel and the bottom, and three at one-quarter the distance from the roof and the floor.

After the engines of the automobiles had been operated for a definite length of time a number of men entered the experimental tunnel, opened the top stopcock of the pipettes, placed pitchers under the bottom stopcock and then opened the latter, allowing the mercury to flow into the pitchers. As the mercury ran out the pipettes were filled with the air and other gases in the tunnel. When the mercury had left the pipettes both stopcocks were closed. In this way eighteen samples of the contaminated air at a like number of points uniformly distributed throughout the tunnel were obtained for each test. These samples were then analyzed.

Solutions were employed for the absorption of the components of the contaminated air to determine the relative quantities of the following:

I. Carbon dioxide.

2. Unsaturated hydro carbons.

3. Oxygen.

4. Carbon monoxide.

The residue unabsorbed was assumed to be nitrogen.

From a very elaborate and convincing analysis Professor Alleman reported that when all doors were closed and the ventilators open and exhausting from the top of the tunnel, and after the engines of eight cars had been "running light" for forty minutes, the condition of the atmosphere was almost normal so 
far as physiological action was concerned and the carbon-monoxide content not dangerous. This conclusion was further supported by the fact that the eighteen persons who remained in the tunnel during the test for a continuous period of forty minutes experienced no unpleasant sensations from breathing the air and no subsequent distress.

The contaminated air analysis for this particular test was as follows:

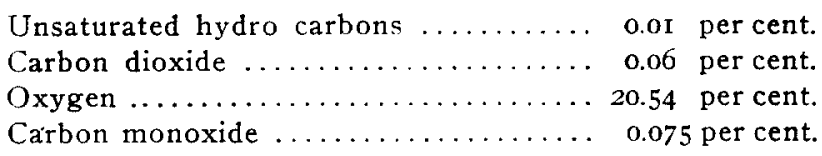

which proved that the percentage of carbon monoxide was so small as to be negligible.

From the data obtained it was figured that supply fans with a maximum capacity of 360,000 cubic feet of fresh air per minute and the exhaust fans some twenty per cent. more capacity would be required to ventilate the tunnel. In all it was figured to provide a maximum of $75^{\circ}$ horsepower to operate these fans and the maximum static pressure that the supply fans would be required to operate against was five inches to six inches.

The system of exhaust and supply fans in the tunnel was to operate from four stations:

One to be situated between the portal and the fresh or foul air shafts (built at the bulkhead line) on the New Jersey side and ventilating this approach only.

One at the base of the New Jersey shafts and ventilating that portion to the centre line of the tunnel.

One station on the New York side, duplicate of that at the base of the New Jersey shafts.

One midway between the New York shafts and the New York portal, ventilating this approach only.

The first, second and third stations were to be equipped with both supply and exhaust fans, and the fourth station, or that on the New York approach, was to have exhaust fans only, since this approach was but 1400 feet long.

The fans at the various stations were to be made up of several small units so that air quantities could be varied according 
to the traffic and thereby keep down the cost of ventilating to a minimum.

In the early part of the year 19I7 Mr. Thomas N. McCarter, President of the Public Service Corporation of New Jersey, made public the tunnel report, hereinbefore referred to, which had been prepared for that Corporation by experts retained by it. The Company's purpose, as explained by Mr. McCarter, was not to advocate any special plan but to demonstrate the feasibility of a tunnel from practical engineering and financial standpoints and to urge that one be constructed as soon as possible by the States of New York and New Jersey. His idea was to show that if the tunnel were not operated as a free public highway, similar to the bridges over the East River, it could be profitably operated as a private enterprise and that highly favorable results would be obtained.

He explained that his corporation had no selfish interest in the proposition as a profit-bearing utility, but was heartily in favor of the project, because it would spell progress for metropolitan New York and the whole State of New Jersey. All of the data obtained by the corporation at its own expense were placed gratuitously at the disposal of the Interstate Bridge and Tunnel Commission, and the public authorities were put on notice that if the governmental agencies did not act within a reasonable length of time after the return to normal business conditions, the corporation would seek State authority to finance and operate the project on its own account, charging tolls as a means of reimbursing itself for its investment.

Since that time, as well as before, the proposition has been given serious consideration by the Interstate Bridge and Tunnel Commissions of New York and of New Jersey. In New Jersey legislation has been enacted to enable the State to join with $\mathrm{New}$ York in the construction and operation of a tunnel. Like arrangements are under consideration by the State of New York. Besides, there is a bill now before Congress that provides for $\$ 6,000,000$ as the Federal Government's contribution toward the construction of this tunnel.

It is hoped with peace at hand and industrial conditions readjusting themselves, this much needed improvement, that will affect the convenience, the comfort and the cost of living of $7,000,000$ inhabitants, will be carried to fruition. 